\title{
Antes del espacio público: una historia de los espacios verdes y libres de la ciudad de Rosario (1900-1940)
}

Before the public space: a history of green and open spaces in Rosario city (1900-1940)

\author{
Diego Roldán* \\ Sebastián Godoy ${ }^{* *}$
}

\begin{abstract}
Resumen
Este trabajo parte de constatar la proliferación del concepto de espacio público en el lenguaje político, proyectual y cultural urbano actual. Posteriormente, se interroga acerca de si esa multiplicación y derrame del concepto de las últimas décadas tuvo algún correlato o equivalente en el pasado. El artículo comprueba que, al menos en la ciudad de Rosario, el espacio público como designación aplicable a un espacio urbano específico es un fenómeno relativamente nuevo, que no puede remontarse más allá de las tres últimas décadas. Este estudio se propone reconstruir históricamente las designaciones y los sentidos producidos alrededor de y atribuidos a los espacios verdes en tanto dispositivos urbanos. El higienismo, el paisajismo y el urbanismo son las tres formaciones discursivas y momentos históricos que construyen el acceso para reflexionar acerca de la relación que los espacios verdes y los espacios libres, en tanto dispositivos higiénicos, paisajísticos y urbanísticos, plantean con los significantes actualmente asignados al espacio público. Se demuestra que entre los espacios verdes y los espacios públicos existe una relación marcada por la diferencia, la discontinuidad y el desplazamiento.
\end{abstract}

Palabras clave: Urbanismo; Espacio Público; Paisaje; Higiene; Parques.

\begin{abstract}
From the proliferation of public space in the political, projective and cultural urban languages, this work analyses the projection of this concept in historical terms. The article notes that, strictly speaking, the public space as a designation applicable to a specific urban space is a relatively new phenomenon, which can't go back beyond the last three decades. This study aims to reconstruct historically produced designations and cultural meanings around and attributed to green spaces in both urban devices. Matrices hygienist, landscaper and urbanism are the three discursive formations and historical genealogical moments used to reflect about the relationship that green spaces and open spaces, while hygienic, landscape and urban devices pose with signifiers currently assigned the public space. It is shown that between green spaces and public spaces there is a relationship marked by difference, discontinuity and displacement.
\end{abstract}

Keywords: Urban design; Public Space; Landscape; Higiene; Parks.

\footnotetext{
Doctor en Humanidades y Artes por la Universidad Nacional de Rosario - Argentina. Investigador Adjunto del Consejo Nacional de Investigaciones Cientìficas y Técnicas. Director del Centro de Estudios Culturales Urbanos de la Facultad de Humanidades y Artes de la Universidad Nacional de Rosario. Profesor Titular de la Cátedra de Espacio y Sociedad la Universidad Nacional de Rosario - Argentina.

** Doctorando en Humanidades por la Universidad Nacional de Rosario. Investigador del Centro de Estudios Culturales Urbanos y Jefe de Trabajos Prácticos de la Cátedra de Espacio y Sociedad en la Facultad de Humanidades y Artes de la Universidad Nacional de Rosario. Becario del Concejo Nacional de Investigaciones Científicas y Técnicas. Profesor en la Universidad Nacional de Rosario - Argentina.
} 


\section{Introducción}

A lo largo de los últimos treinta años y en el marco del discurso político urbano, el espacio público ha incrementado su presencia y valor como forma material, voluntad política y representación cultural. Esta centralidad convirtió al espacio público en uno de los principales vectores de apropiación y democratización de la ciudad. Actualmente, el espacio público se ubica en un punto neurálgico de la agenda de los gobiernos locales (BORJA, 2012). Pero cabe interrogarse acerca de si esa posición medular del concepto de espacio público acompañó desde siempre los diseños de la regulación y planificación urbanas del siglo XX.

Desde fines de los años 1980s., se ha formado un consenso que apunta a construir más y mejores espacios públicos, pero que, al mismo tiempo, obstaculiza la reconstrucción tanto de la historicidad del concepto como de la forma urbana que lo encarna. Por lo tanto, hubo poco lugar para la interrogación histórica o para la construcción de una genealogía localizada de estos espacios materiales y conceptos culturales y políticos. Justamente, al declinar una posible indagación histórica sobre este problema, el espacio público devino un concepto político y un artefacto cultural y urbano indiscutible que, paradójicamente, resulta capaz de producir una ciudadanía consensual, vaciada en los moldes de una administración municipal que se mantiene a distancia de las arenas de lucha, conflicto y debate. De este modo, el espacio público queda encriptado en una suerte de limbo que lo ubica más allá de lo cuestionable, lo pensable y lo debatible. Esto provoca un efecto paradojal, puesto que una de las justificaciones del dispositivo urbano del espacio público es la producción de valores cívicos. Obnubilados por su presunta naturaleza benéfica, técnicos, políticos y científicos sociales parecen no percibir del todo claramente en el espacio público un dispositivo urbanístico construido sobre la base del conflicto, la desigualdad y la polarización de las ciudades.

En sintonía con esta idea, Adrián Gorelik (2008) afirmó la existencia de un romance del espacio público. Ese idilio, organizado alrededor de este concepto y del que participan la sociedad civil, el estado y los técnicos urbanistas, entraña el peligro de reificarlo. En este contexto de exaltación, se atribuye al espacio público la capacidad de "construir ciudadanía”, escenificar las "buenas prácticas de gobierno", borrar las diferencias y desigualdades $\mathrm{o}$, al menos suspenderlas temporariamente, en pro de cohesionar una imagen de la ciudad operable a través del marketing urbano (GARCÍA 
CANCLINI, 1998; DELGADO, 2007). El espacio público es hoy invocado por un amplísimo espectro político relacionado con la gestión urbana. Tan convocante es ese arco que no sólo involucra a los funcionarios y los técnicos-urbanistas, sino que abarca también a los propios inversores, especuladores y promotores urbanos. En la gestión urbana contemporánea, no existe ninguna posibilidad de presentar cualquier tipo de Plan Estratégico sin recurrir a la idea de ampliar la construcción, la accesibilidad y los usos de espacios públicos de alta calidad. Torciendo un texto clásico de Jürgen Habermas (1986), Manuel Delgado (2011, p. 10) ha planteado que el espacio público de la planificación estratégica catalana es sobre todo una ideología. El antropólogo afirmó que el espacio público es una formación discursivo-arquitectónica que bajo los ropajes de un supuesto comunitarismo busca encubrir "[...] la reapropiación capitalista y burguesa de la ciudad”. El sentido del espacio público se produce en la gestión urbana contemporánea como una especie de simulacro en los términos que Baudrillard (1978) atribuye a la hiperrealidad y que Derrida (1995) le asigna al espectro.

No obstante, la trayectoria del concepto de espacio público describe cierta complejidad. Algunas tradiciones de pensamiento homologaron lo público con lo estatal, ubicando su nacimiento en el ocaso del Ancien Regime europeo, cuando la Revolución Francesa habría creado desde arriba una nueva realidad pública, claramente diferenciada del ámbito privado, para los ciudadanos (SENNETT, 1977; HENAFF; STRONG, 2001). A mediados del siglo XX, las obras de Arendt (2007) y Habermas (1982) habían invertido esa correlación. Tanto en La condición humana como Historia y crítica de la opinión pública, lo público aparece como un espacio político para la defensa de los ciudadanos y la sociedad civil frente al avance de la razón de estado. Una tónica similar se mantuvo durante los primeros pasos de la restauración de las garantías democráticas post-1983 en la Argentina. En rigor, la conceptualización de esfera o espacio público se circunscribió a la cuestión de la política moderna, utilizando la designación conceptual de espacio o esfera pública (CHARDON, 2011). Pero en las últimas tres décadas esa polaridad relacional quedó invertida, en parte, a consecuencia de la reforma del Estado argentino ocurrida en la primera parte de la década de 1990.

Desde mediados de los años 1990s., el espacio público aparece como una cuestión estatal o, más precisamente, municipal, que involucra terrenos específicos que se encuentran bajo jurisdicción municipal o metropolitana. Al desembarcar en la Argentina las nuevas políticas locales, hijas de la descentralización neoliberal, la cogestión público-privada, el marketing urbano y el planeamiento estratégico catalán, el 
espacio público dejó de revistar en el campo de la filosofía política, declinó su vinculación con la sociedad civil y se materializó en el equipamiento urbano diseñado por urbanistas-técnicos locales o extranjeros y financiado por convenios públicoprivados (VAINER, 2009). Al mismo tiempo, el espacio público desplazó y sustituyó a las designaciones anteriores de espacios libres o espacios verdes que figuraban en los planos y las planificaciones urbanas de la primera mitad del siglo XX y de espacios recreativos del urbanismo funcionalista, en apogeo tras la segunda posguerra.

En este trabajo procuramos mostrar la alteridad que ofrecen los primeros ensayos de organización urbana los espacios verdes y espacios libres frente al concepto actual de espacio público. ${ }^{1}$ En este sentido, nos concentraremos en las maneras en que fueron concebidos estos espacios desde comienzos del siglo XX, en la ciudad de Rosario. Esta urbanización ha sido reivindicada como un territorio propicio para y un modelo exitoso de construcción de espacios públicos planificados en la República Argentina y la interpretación oficial establece cierta línea de continuidad entre las primeras intervenciones y los diseños más recientes (PLAN URBANO ROSARIO, 2008). En las páginas siguientes, revisaremos el impacto de la matriz higienista, puesta en acto en el Parque de la Independencia de 1900. Luego, analizaremos la visión estético-distintiva de estos espacios encarnada por la perspectiva paisajista del Plan Bouvard de 1911 y del Parque de Recreo Ludueña de Charles Thays. Estos primeros ensayos serán seguidos por los desarrollos iniciales de estos espacios verdes ideados en el marco de los intentos de formalizar al urbanismo como disciplina científica (RIGOTTI, 2015). Interrogando diversos materiales históricos de archivo, el abordaje se propone aportar algunos elementos empíricos para reflexionar acerca de una historicidad y una genealogía posible y localizada, en el sentido de discontinuidad, ruptura, alteridad y multiplicidad (GADAMER, 1996; FOUCAULT, 1988) del concepto de espacio público aplicado al suelo urbano en la ciudad de Rosario durante las primeras décadas del siglo XX.

\footnotetext{
${ }^{1}$ El concepto de espacios verdes pertenece al vocabulario urbano del Municipio de Rosario y al de los técnicos que confeccionaron su primer Plan Regulador en 1935 (DELLA PAOLERA, GUIDO; FARENGO, 1935) y se entronca con una tradición que vincula urbanismo e higienismo. La noción de espacios verdes es introducida por Werner Hegemann en sus conferencias sobre Rosario a comienzos de los años 1930s. y se entronca con la tradición berlinesa de planificación urbana cuya autonomía respecto al discurso médico resultaba más marcada Crasemann Collins (2005).
} 


\section{El espacio verde como dispositivo higiénico y distinción}

Las dos obras clave del higienismo argentino fueron publicadas entre $1876 \mathrm{y}$ 1878. En sus páginas, Guillermo Rawson y Eduardo Wilde propusieron los tópicos fundamentales de lo que denominaron higiene pública. Difundida desde Francia, esta rama de la "medicina práctica" se pensaba a sí misma como una suerte de higiene preventiva aplicada a los grupos sociales más vulnerables del espacio social. En palabras de Wilde (1885, p. 8), la higiene pública era la higiene de los pobres. El higienismo definió como terreno de intervención a la trama urbana. La vida en las ciudades exhibía algunas características indeseables. Una buena parte de la población vivía hacinada en los reducidos cuartos de los conventillos. Tampoco los suburbios eran espacios higiénicamente saneados, ante los que la vida rural aparecía casi como un paraíso perdido. A pesar de cierto tono tradicional y una vida cultural apacible, las comparaciones entre los habitantes de la ciudad y los del campo mostraban a estos últimos con mejor constitución y salud física. Frente al campo abierto, los conventillos sombríos, húmedos, fríos y con pésimos servicios y equipamientos colectivos, resultaban inadecuados. El inquilinato fue observado como una maquinaria productora de enfermedades. Con la única ventaja de su localización excéntrica, la viviendas populares ubicadas en la periferia constituían otro foco de infección formado por lo que las urbanizaciones céntricas, las casas lujosas, las industrias, talleres y establecimientos insalubres descartan en sus suelos y aguas (PASCUAL, 2015). A mediados del siglo XIX, Engels $(1965 ; 1974)$ había notado en Manchester, al mismo tiempo siguiendo y discutiendo con los médicos higienistas, que el suelo que pisan, el agua que beben y el aire que respiran los pobres no son los mismos ni poseen las idénticas propiedades al de los que conforman el ambiente de las clases acomodadas. En su clásico estudio sobre las casas de inquilinato, Rawson (1885) observó y sopesó las posibilidades y estrategias para mejorar su situación higiénica. La normativa para regularizar y mejorar las condiciones sanitarias de los conventillos debía complementarse con una política de producción de viviendas baratas para obreros y la construcción de amplias avenidas y parques. La respuesta estético-higiénica a los males urbanos configuró un dispositivo que buscó hacer actuar en consonancia a los árboles, los jardines, los pequeños bosques, las pérgolas, los lagos, los juegos infantiles, las fuentes ornamentales, los kioscos de música y los centros de recreación. 
En Rosario, estas proposiciones ejercieron una influencia significativa. El debate entre Sarmiento y Rawson, alrededor de la localización y la accesibilidad del Parque 3 de Febrero de Buenos Aires (actualmente, Palermo), provocó notables ecos locales. Para Sarmiento, el parque era ante todo un dispositivo cívico que intentaba borrar de Buenos Aires la herencia rosista (GORELIK, 1998). La obsesión sarmientina por erradicar todo vestigio de la "barbarie" de la ciudad de Buenos Aires, incluido el caserón de Rosas, no reparó en la ubicación demasiado retirada, las características inadecuadas de los terrenos y las dificultades del trasporte para dar acceso a los sectores populares. Todas estas objeciones fueron esgrimidas por Rawson, quien afirmaba la necesidad de convertir al parque en un espacio para la oxigenación, vivificación e higienización de los organismos populares. A los argumentos higiénicos, agregaba las virtudes democráticas de un parque equidistante de la aglomeración residencial. Rawson (1876) había descubierto las formas democratizadoras de los espacios verdes y paseos públicos urbanos en su viaje a la Exposición Universal de Filadelfia, cuando tuvo oportunidad de visitar Nueva York y recorrer el Central Park. Las virtudes curativas del verde (ARMUS, 1996) debían estar al servicio de las poblaciones populares, el parque necesitaba reunir una diversidad de públicos y armonizar una multiplicidad de organismos y grupos sociales. El parque como dispositivo higiénico gravitaba sobre la noción de población que desde el punto de vista sanitario necesitaba ser vivificada y desde la estadística, conservada (FOUCAULT, 2006).

En su viaje a Europa, con motivo de la Exposición Universal de París de 1889, el letrado rosarino Gabriel Carrasco, ferviente admirador de Sarmiento, tuvo oportunidad de recorrer los squares y parques de Londres. Embelesado, manifestó su vocación por replicar la profusión, distribución y accesibilidad de espacios verdes en las ciudades argentinas.

\footnotetext{
No sé cuántos parques, plazas y jardines públicos hay en Londres, pero juzgo que deben contarse por centenares, tal es la profusión con que por todas partes se les encuentra. Si esto se ha hecho aquí, en una ciudad situada en un clima cuyo invierno es crudo, júzguese lo que debería hacerse en Buenos Aires, en el Rosario, y en nuestras demás ciudades argentinas, que tienen un clima casi tropical! (CARRASCO, 1890, p. 325).
}

En Rosario, las posibilidades de materializar un espacio verde de grandes dimensiones se generaron durante la intendencia de Luis Lamas. A comienzos del siglo XX, Lamas construyó la oportunidad inmobiliaria, movilizó los recursos políticos y canalizó las ambiciones de las clases dominantes para expropiar los terrenos que darían 
lugar a un gran parque central. Al iniciarse el siglo pasado, los promotores y principales usuarios del parque vivían en sus inmediaciones, sobre uno de los bulevares de ronda que configuraba el vértice noroeste de su extensión. Ellos deseaban ambientar su vida urbana con las bellezas y la tranquilidad naturales. Para llenar ese anhelo, el parque aparecía como el dispositivo más adecuado: la interface urbana de integración del campo a la ciudad. Las experiencias londinenses y parisinas eran los paradigmas evocados por la retórica y la planimetría de estos proyectos. Las clases dominantes soñaron con establecer diques de contención para las masas que quisieran ingresar al parque, querían convertirlo en un espacio exclusivo. Imaginaron un paseo organizado en correlación al bulevar, donde las clases dominantes pudieran observar y ser observados, ostentar sus carruajes, trajes y vestidos, la presencia de las clases subalternas sólo podía oficiar como una suerte de paisaje humano, espectadores completamente pasivos y de segundo orden. La organización scópica del paseo colocaba las condiciones de visibilidad de las clases subalternas fuera del escenario principal e incluso más allá de las primeras líneas de espectadores. Sin embargo, la identidad de las clases dominantes necesitaba de la presencia de estos subalternos para poder reafirmar, reforzar y actualizar los privilegios derivados de su posición social y simbólica.

Quizá a raíz de esos tributos exigidos por la identidad de las clases dominantes, de esa obsesión por el sostenimiento y la exhibición de las jerarquías sociales, la higiene pública y las poblaciones populares fueron invocadas a la hora de justificar las inversiones en la construcción del Parque de la Independencia. Los significantes de la higiene pública fueron esclarecidos por los datos de las estadísticas de mortalidad, recopiladas por los gobiernos de las ciudades que habían construido grandes parques, fundamentalmente, Nueva York, Londres y París. Con una demostración basada en costos-beneficios, se justificaba la inversión del gobierno en la expropiación y el acondicionamiento de las tierras. Lamas afirmaba que los parques no sólo serían un espacio para la contemplación estética de la naturaleza, una expansión de los jardines privados, un predio ferial para las exhibiciones de los productos del progreso agropecuario, comercial e industrial de la nación, sino también unas barreras eficaces para contrarrestar el efecto de las enfermedades y mantener a la población saludable y económicamente activa.

Y he ahí porque se hace necesaria la adquisición de una zona de terreno donde se levante un Parque y se hagan plantaciones que purifiquen la atmósfera donde se efectúen exposiciones periódicas de la producción ganadera, agrícola y fabril de la provincia, se fomente los ejercicios atléticos 
e hípicos que han sido aceptados como una manifestación de progreso y que causan la diversión de las sociedades modernas. Es una idea que se impone en el espíritu del administrador, del que tenga un vínculo que lo ligue al municipio, del que tenga un noble interés en su adelanto y finalmente del hijo de este pueblo que desee aproximarlo a la felicidad. (ARCHIVO MUNICIPAL DE DIGESTOS Y ORDENANZAS DE ROSARIO, 24 jun. 1900, f. 292). ${ }^{2}$

La retórica de Lamas alcanzó para convencer a los funcionarios provinciales de emprender las expropiaciones necesarias para la formación del parque. Una parte muy considerable de la superficie fue cedida al Jockey Club de Rosario, que la destinó a la construcción de un importante hipódromo y otra, algo más reducida, a la Sociedad Rural de Rosario que formó un predio ferial y de exposiciones con carácter permanente. La concesión de terrenos fue la fórmula que el gobierno municipal halló para financiar y sostener un parque quizá demasiado amplio para el presupuesto reducido de la Dirección de Parques y Paseos. Así como las clases subalternas se beneficiarían de la purificación del aire por obra del parque, los atractivos del paseo se incrementarían a causa de las actividades y los acondicionamientos de los concesionarios que organizarían la naturaleza para el deleite de los ciudadanos. Los artificios sociales no sólo civilizarían el terreno, sino que acondicionarían y mantendrían algunas zonas del parque en buen estado sin el concurso financiero del municipio. En las dos primeras décadas del siglo XX, las instituciones concesionarias y las superficies concesionadas se multiplicaron: en 1904, el Club Argentinos (luego bautizado Gimnasia y Esgrima); en 1906, Club Atlético Provincial; en 1910, Club Atlético Newell’s Old Boys; en 1916, Estudiantes Football Club. A estas instituciones se agregaban algunos predios con objetivos específicos que fueron construidos por instituciones públicas: Parque Escolar 1914 y Stadium Municipal 1925. A mediados de los años 1920s., al constatar que casi el $70 \%$ de la superficie total del parque había sido concesionada, esta operatoria no se amplió (ARCHIVO MUNICIPAL DE DIGESTOS Y ORDENANZAS DE ROSARIO, 10 may. 1923 , f. 199) ${ }^{3}$ aunque no se revirtieron las medidas y la mayor parte de las concesiones aún hoy se mantienen vigentes.

\footnotetext{
2 ARCHIVO MUNICIPAL DE DIGESTOS Y ORDENANZAS DE ROSARIO. Expedientes Terminados del Honorable Concejo Deliberante. "El intendente Lamas sobre el Parque Independencia". 24 jun. 1900, f. 292.

3 ARCHIVO MUNICIPAL DE DIGESTOS Y ORDENANZAS DE ROSARIO. Expedientes Terminados del Honorable Concejo Deliberante. Diciembre 1923, t. 2. "Director de Parques y Paseos contesta petición del Club Sportivo solicitando terreno en el Parque Independencia”. 10 may. 1923, f.199.
} 


\section{Imagen 1 - Plano Parque de la Independencia ${ }^{4}$}

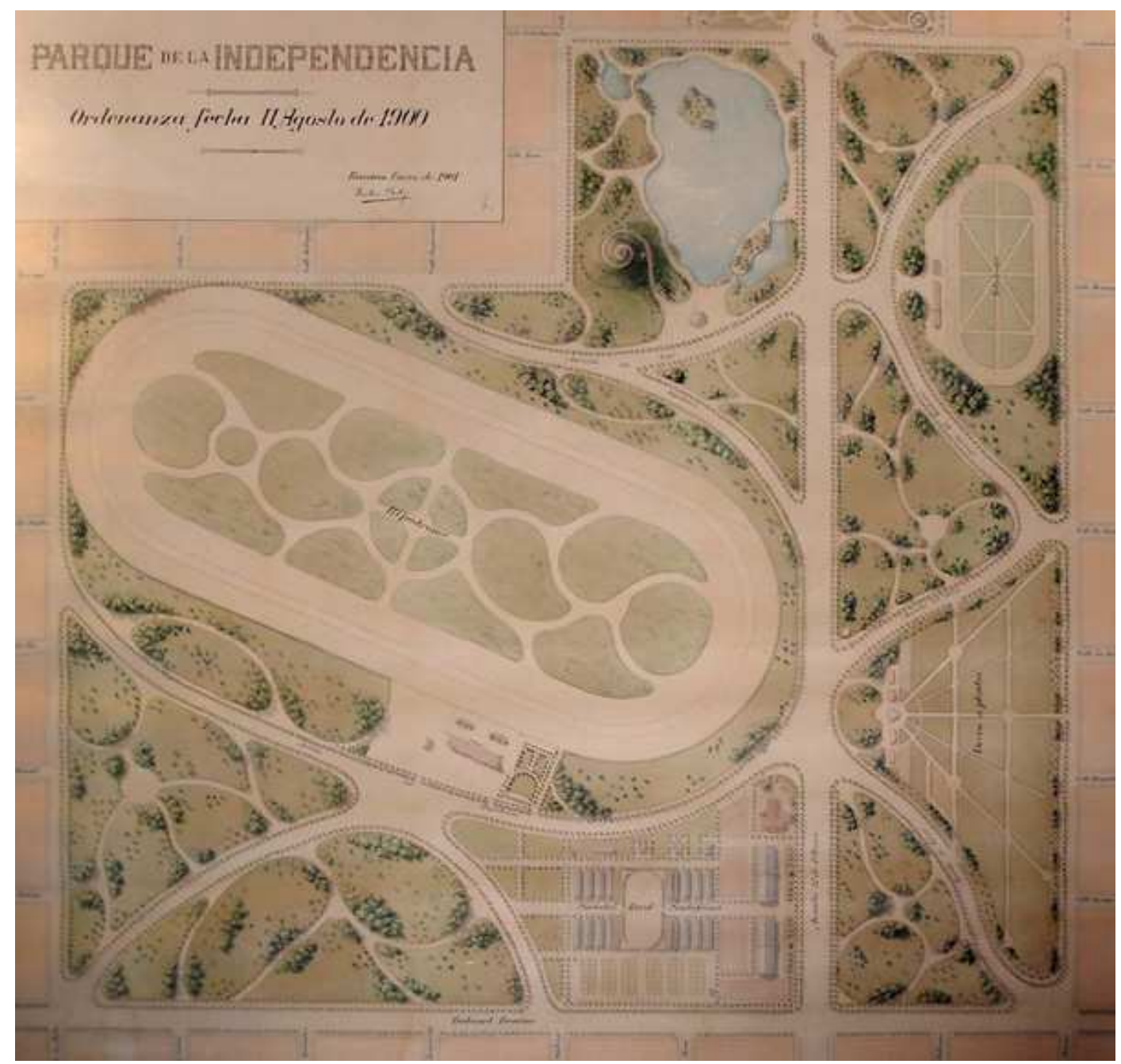

Fuente: Archivo del Museo de la Ciudad.

\section{El espacio verde como dispositivo paisajístico-recreativo}

Paralelamente, los proyectos del municipio sobre el embellecimiento urbano y la construcción de otros espacios verdes se incrementaron alrededor de la zona norte. En vísperas del Centenario de la Revolución de Mayo de 1810, el intendente Isidro Quiroga (1909) convocó al Ingeniero y Arquitecto Joseph Bouvard para “[...] proyectar un plan general para la futura delineación y aprovechamiento de las bellezas naturales de la ciudad." (ARCHIVO MUNICIPAL DE DIGESTOS Y ORDENANZAS DE

\footnotetext{
${ }^{4}$ Se destacan los espacios reservados para usos específicos: el Hipódromo, el lago, el predio de la Sociedad Rural y la pista para ciclismo del Velóz Club.
} 
ROSARIO, 4 oct. 1909, f. 308) ${ }^{5}$. El Director Administrativo de los Servicios de Arquitectura, Paseos y Plantaciones de la ciudad de París aceptó la propuesta a cambio de $\$ 15.000 \mathrm{~m} / \mathrm{n}$. El 10 de marzo de 1911, Bouvard remitió los planos acompañados por una breve memoria descriptiva. El ingeniero caracterizó el desarrollo de la ciudad como rápido y afirmó que los problemas urbanos que enfrentaba eran los propios de la imprevisión de ese crecimiento acelerado.

[...] se han preocupado solamente del presente y nada del porvenir [...] las numerosas líneas del ferrocarril serán desde el presente y más aún en el porvenir un obstáculo serio a las mejoras a realizarse para el engrandecimiento de la ciudad. (ARCHIVO MUNICIPAL DE DIGESTOS Y ORDENANZAS DE ROSARIO, 10 mar. 1911, f. 353). ${ }^{6}$

Asimismo, Bourvard notó que era necesario “crear plazas públicas” y mejorar el trazado y la conectividad de la red de calles. Algunos de estos acondicionamientos estaban directamente orientados a aprovechar “[...] una riqueza natural panorámica como la del río Paraná y sus barrancas, sacar partido de esos puntos pintorescos para el deleite del público." (ARCHIVO MUNICIPAL DE DIGESTOS Y ORDENANZAS DE ROSARIO, 10 mar. 1911, f. 354) ${ }^{7}$. Si bien, como era común en materia de proyectiva urbana, la incidencia de este plan fue más simbólica que material, Bouvard destacó algunos de los problemas que preocuparían a otros urbanistas convocados para ejercer el arte y la técnica de regular la ciudad. Aunque las resoluciones propuestas fueron muy diferentes, las cuestiones del tráfico vial, las barreras que suponían los ferrocarriles y las instalaciones portuarias y la escasa disponibilidad de espacios verdes fueron materia de reconsideración permanente por parte de sus sucesores.

También hacia el Centenario, el municipio manifestó su intención de comprar unos terrenos para proyectar un parque en la zona norte de la ciudad, en las inmediaciones del Paraná (ARCHIVO MUNICIPAL DE DIGESTOS Y

\footnotetext{
5 ARCHIVO MUNICIPAL DE DIGESTOS Y ORDENANZAS DE ROSARIO. Expedientes Terminados del Honorable Concejo Deliberante. Octubre 1909. "El intendente Quiroga sobre Joseph Bouvard y un plan para Rosario". 4 oct. 1909, f. 308.

6 ARCHIVO MUNICIPAL DE DIGESTOS Y ORDENANZAS DE ROSARIO. Expedientes Terminados del Honorable Concejo Deliberante. Mayo 1913, t. 1. "Presentación del Plano de Rosario de Joseph Bouvard frante al Concejo Deliberante”. (París) 10 mar. 1911, f. 353-354.

7 ARCHIVO MUNICIPAL DE DIGESTOS Y ORDENANZAS DE ROSARIO. Expedientes Terminados del Honorable Concejo Deliberante. Mayo 1913, t. 1. "Presentación del Plano de Rosario de Joseph Bouvard frante al Concejo Deliberante”. (París) 10 mar. 1911, f. 353-354.
} 
ORDENANZAS DE ROSARIO, 1 abr. 1910, f. 327) ${ }^{8}$. Las dimensiones de los terrenos eran más modestas, apenas alcanzaban las 4 hectáreas, y el precio tampoco fue el más conveniente, $\$ 7$ por metro cuadrado (ARCHIVO MUNICIPAL DE DIGESTOS Y ORDENANZAS DE ROSARIO, 11 ago. 1910, f. 131) ${ }^{9}$. La compra se realizó a la sociedad anónima "El Arroyito", la empresa urbanizadora del barrio homónimo, cuya experiencia en el negocio inmobiliario era amplia (LANCIOTTI, 2009). El mercado del suelo atravesaba un buen momento y, con motivo del Centenario, las obras públicas estaban a la orden del día. Los agentes municipales se mostraron entusiasmados con la posibilidad de habilitar un espacio verde en las cercanías de la ribera. Charles Thays fue el encargado de proyectar lo que se denominó Parque de Recreo Arroyito. Entre las consideraciones del ingeniero y paisajista francés estaba volver a colocar a disposición de los habitantes de Rosario una obra de menor tamaño, aunque semejante en su naturaleza e intención, a la realizada durante la intendencia Lamas con el Parque Independencia. Thays presupuestó los acondicionamientos necesarios para el terreno, la plantación de diversas especies y la construcción de un servicio de riego. El parque constaba de una gran terraza mirador que no solo proporcionaría una vista extraordinaria del río, sino que tenía la ventaja material de ser lo suficientemente robusta para resistir sus embates y crecidas. Los equipamientos del parque serían numerosos y lo presentaban como un lugar destinado al ocio de las clases dominantes de Rosario; algunos de sus miembros habían construido pequeñas mansiones en el cercano Pueblo Alberdi. Al ser el predio más circunscripto, las actividades a desarrollarse en él no preveían grandes superficies a concesionar como ocurriera, pocos años atrás, en el Parque de la Independencia. Además de la Gran Terraza, las superficies del Parque Recreo Arroyito estarían dotadas de construcciones orientadas a mejorar el atractivo y los entretenimientos del lugar: confitería; cinematógrafo; tribuna; monumentos varios; kiosco para música; gimnasio (ARCHIVO MUNICIPAL DE DIGESTOS Y ORDENANZAS DE ROSARIO, 23 sept. 1913, f. 175). ${ }^{10}$

\footnotetext{
8 ARCHIVO MUNICIPAL DE DIGESTOS Y ORDENANZAS DE ROSARIO. Expedientes Terminados del Honorable Concejo Deliberante. Mayo 1910, t. 2. "Boleto de Compra venta ad Referéndum de terrenos para la construcción del Parque Arroyito”. 1 abr. 1910, f. 327.

9 ARCHIVO MUNICIPAL DE DIGESTOS Y ORDENANZAS DE ROSARIO. Expedientes Terminados del Honorable Concejo Deliberante. Agosto-diciembre 1910, t. 2. "La Sociedad Anónima el Arroyito disponiendo la venta de terrenos a la Municipalidad para la formación del Parque Arroyito". 11 ago. 1910 , f. 131.

10 ARCHIVO MUNICIPAL DE DIGESTOS Y ORDENANZAS DE ROSARIO. Expedientes Terminados del Honorable Concejo Deliberante. Mayo 1913, t. 2. "Secretario de la Intendencia eleva el proyecto del Ing. Carlos Thays del Parque Recreo Arroyito”. 23 sept. 1913, f. 175.
} 
Con la irrupción de la Primera Guerra, las finanzas del municipio quedaron seriamente comprometidas. El presupuesto asignado al proyecto del Parque Recreo Arroyito fue recortado. En 1917, cuando aún se estaban realizando tareas de desmonte de la barranca, mejora de los terrenos y de construcción de un murallón para evitar que las obras fuesen malogradas por las crecidas, se reestructuraron los planos de Thays. Los nuevos trazos, privados de toda ornamentación, mostraron que el horizonte de reformas estaba determinado por la austeridad y la modestia (ARCHIVO MUNICIPAL DE DIGESTOS Y ORDENANZAS DE ROSARIO, 23 abr. 1917, f. 263) ${ }^{11}$. En los años 1920s., la operatoria de concesiones, que caracterizó al Parque de la Independencia, hizo pie también en el Parque de Recreo Arroyito y el Club Regatas logró la sesión de los mejores treinta metros con frente al río del predio (ARCHIVO MUNICIPAL DE DIGESTOS Y ORDENANZAS DE ROSARIO, 14 may. 1920, f. 668-672) ${ }^{12}$. Pero ese traspaso a manos privadas, en lugar de ahogar el desarrollo del parque imprimió un nuevo pulso a sus posibilidades. Se propuso la combinación del parque con un balneario municipal. El nuevo parque y balneario se lanzó al uso público en 1922. Sin embargo, después de doce años de postergaciones, la población de la zona norte de municipio continuaba prefiriendo al Parque Independencia. A pesar de su distante localización, el parque central de la ciudad (el Parque de la Independencia) exhibía un acondicionamiento más favorable y atractivo frente a la precariedad del balneario instalado en el Barrio Arroyito.

11 ARCHIVO MUNICIPAL DE DIGESTOS Y ORDENANZAS DE ROSARIO. Expedientes Terminados del Honorable Concejo Deliberante. Mayo 1917. "Terrenos para el Parque Arroyito". 23 ab. 1917 , f. 263.

12 ARCHIVO MUNICIPAL DE DIGESTOS Y ORDENANZAS DE ROSARIO. Expedientes Terminados del Honorable Concejo Deliberante. Mayo 1920, t. 1. "Pedido y Concesión del Club Regatas de terreno municipal en Barrio Arroyito". 14 may. 1920, f. 668-672. 
Imagen 2 - Parque de Recreo Arroyito. Zona ribereña sobre la que se emplazaría el proyecto de Charles Thays, 1912

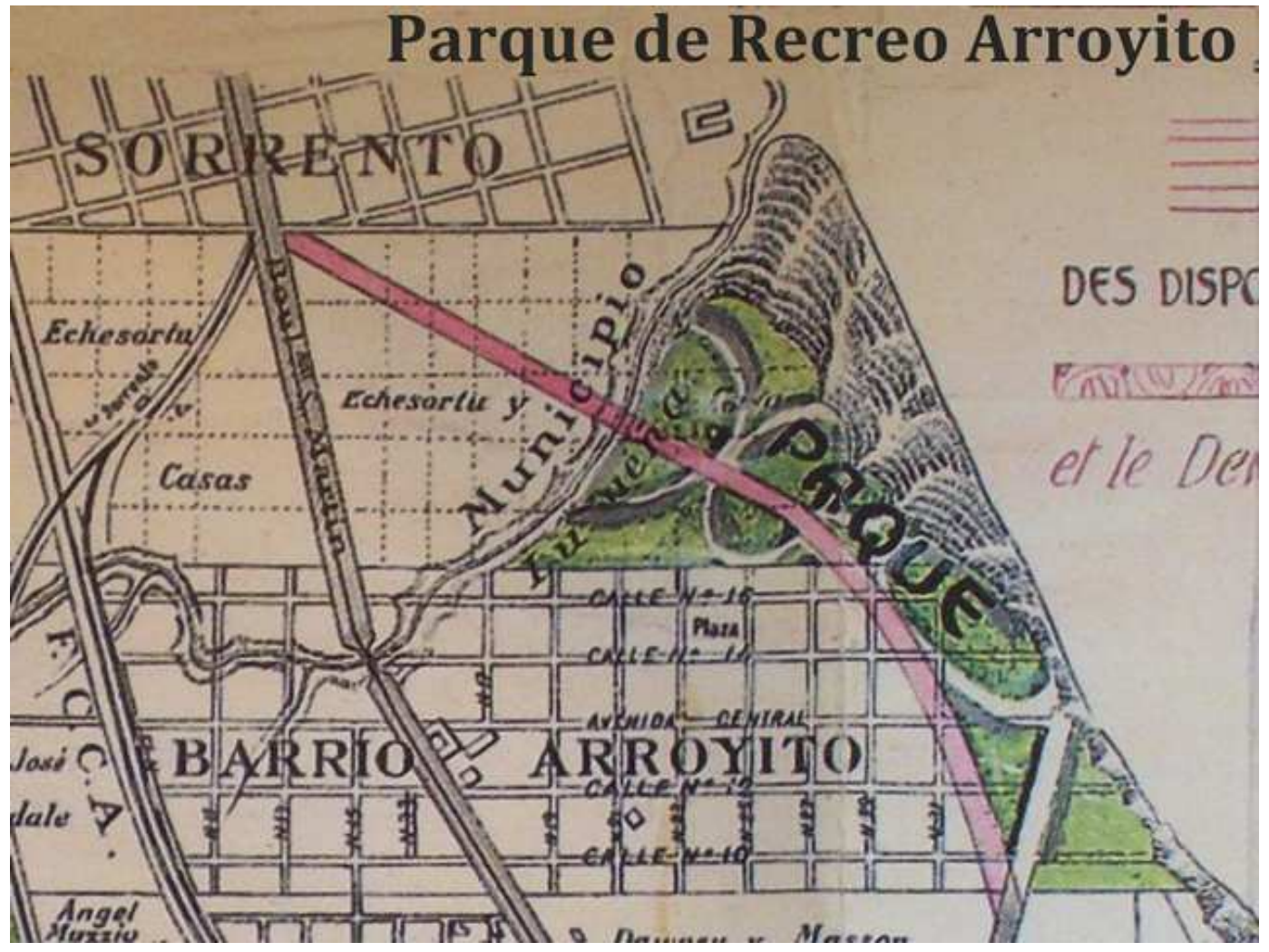

Fuente: Archivo de Digestos y Ordenanzas, Rosario.

En la década de 1920, el municipio promovió la construcción de pequeños espacios verdes que estaban diseminados a lo largo de una trama urbana cada vez más extensa hacia el oeste y el sur. Las pequeñas plazas barriales configuraban la objetivación del deseo de progreso de las sociedades vecinales, alrededor de las que comenzaba a aglutinarse la vida de la sociabilidad política urbana. Algunos funcionarios, influenciados en parte por el escolanovismo y respondiendo a las numerosas solicitudes de los vecinos, proyectaron la renovación del arbolado de las plazas Sarmiento, Buratovich y Belgrano. Asimismo, los miembros de la Dirección de Parques y Paseos diseñaron algunas innovaciones, como el dispositivo para ejercicios físicos y el gimnasio en la Plaza Colón del barrio Roque Sáenz Peña (PIGNETTO, 1927).

Si bien esta readecuación no llegó a concretarse, conforma una evidencia del nuevo rol asignado a los espacios verdes: un papel más vinculado a un principio de cuidado de los cuerpos en movimiento y comprometido en la práctica de la cultura física. Por otra parte, también aparece una idea del espacio verde vinculada a las 
colonias de vacaciones y campamentos infantiles (ARMUS, 2014; ROLDÁN, 2012). Esta forma de espacio verde para la actividad física tensionada por sus finalidades higiénicas y recreativas alcanzó su máxima expresión con la inauguración del Parque Balneario Ludueña. Este parque, abierto al público desde 1939, suponía una remodelación profunda de los terrenos en los que se asentara el Parque de Recreo Arroyito. La reestructuración incluía estacionamientos para vehículos a motor, una gran pileta frente al río con los equipamientos típicos de los balnearios diseñados para la concurrencia dominante en la sociedad de masas.

\section{Los espacios verdes como sistemas en la planificación urbana de entreguerras}

En la segunda mitad de los años 1920 hubo un intenso debate en el Concejo Deliberante de Rosario acerca de la construcción de una nueva estación de ferrocarriles del Central Argentino. Esta discusión replanteó la relación de la ciudad y el río y de sus interfaces portuarias y ferroviarias (ROLDÁN, 2010). En ese marco, se debatió alrededor de la necesidad de generar nuevos espacios verdes en la ciudad. Las visiones se materializaron en proyectos de ordenanza y sus discusiones anexas. El edil e ingeniero agrónomo, Juan Devoto, manifestó sus preocupaciones alrededor del aprovechamiento de los espacios libres. Influenciado por la obra de Thays, en 1932, presentó un proyecto de ordenanza sobre "Reservas boscosas y espacios libres". La propuesta intentaba menguar el peso de la iniciativa privada que, según Devoto, funcionaba como el único criterio de crecimiento "sorprendente y desorbitado" de Rosario y que dejaba a la ciudad "[...] al margen de los más elementales principios del urbanismo moderno". En este contexto, el negocio especulativo resentía el bienestar general, en términos de salud pública y estética edilicia. Apoyándose en los criterios del higienismo y el urbanismo moderno, que tenía el propósito de "velar por la salud pública, fomentar la actividad general, y cuidar de la estética edilicia”, el concejal sugería que "la superficie ocupada por espacios libres debía ser aproximadamente equivalente al 20\% del total." (ARCHIVO MUNICIPAL DE DIGESTOS Y ORDENANZAS DE ROSARIO, s/f, f. 2786) ${ }^{13}$. Hasta el momento, Rosario no había hecho demasiado para mejorar esa situación y, por lo tanto, urgía rectificar ese rumbo. En este punto, la propuesta de Devoto coincidía plenamente con el diagnóstico

13 ARCHIVO MUNICIPAL DE DIGESTOS Y ORDENANZAS DE ROSARIO. Expedientes Terminados del Honorable Concejo Deliberante. Mayo 1932, t. 2. "Reservas boscosas y espacios libres. Proyecto del Concejal Ing. Juan Devoto". s/f, f. 2786. 
elaborado un año antes por el urbanista berlinés Werner Hegemann (1931) que en su visita a Rosario afirmó que la mayor pobreza de la ciudad se incardinaba en la escasez de espacios libres.

La ordenanza estipulaba el acondicionamiento y la parquización de los terrenos que lindaban con los arroyos Ludueña y Saladillo. A través de una ley de expropiaciones solicitada al gobierno provincial, en caso de no contar con la buena voluntad de los privados para la donación de los terrenos. En esa zona, se construirían parques y amplios espacios libres. Meses después, se puntualizaron las funciones que desempeñaría la Dirección de Parques y Paseos para realizar las obras de embellecimiento de plazas y jardines. Asimismo, se buscaría "[...] preservar, con fines científicos y artísticos, [pero] también sentimentales y utilitarios un pedazo de tierra donde nuestra flora primitiva se desarrolle libremente, sin sufrir la acción modificadora de la mano del hombre." (ARCHIVO MUNICIPAL DE DIGESTOS Y ORDENANZAS DE ROSARIO, 2 sept. 1932, p. 979) ${ }^{14}$. Algunas de estas nociones discutidas en el Concejo fueron recuperadas parcialmente en los planteos del Plan Regulador de 1935. En sus páginas, aparecería la tentativa de crear un sistema articulado de grandes espacios verdes y suprimir esas pequeñas plazas de las que se enorgullecían las asociaciones vecinales de los barrios.

Tras la relegación del Plan Bouvard, las diagonales y los espacios verdes mostraron su insuficiencia para solucionar los problemas urbanísticos de Rosario. En un artículo periodístico, Carlos M. Della Paolera (1927), urbanista diplomado en París, calificaba al Plan Bouvard como un ejemplo de "urbanización improvisada", que estiraba la ciudad "diagonalmente hasta cobrar forma de rombos" e instaba a las autoridades municipales a considerar la posibilidad de emprender un plan integral de reestructuración urbana.

En 1927, se presentó un proyecto al Concejo Deliberante que preveía la formación de una comisión para elaborar un Plan Regulador para Rosario. El acelerado crecimiento de la edificación, el aumento de vehículos modernos, la desconexión entre el norte y sur de la ciudad obrada por el ferrocarril y la proliferación de aglomeraciones humanas imponían una racionalización integral del tejido urbano. A partir de esa convicción, se organizó una encuesta contestada por profesionales argentinos y

\footnotetext{
${ }^{14}$ ARCHIVO MUNICIPAL DE DIGESTOS Y ORDENANZAS DE ROSARIO. Diario de Sesiones del Honorable Concejo Deliberante. 1932. "Proyecto de ordenanza del concejal Galaretto sobre funciones de la dirección de Parques y Paseos". 2 sept. 1932, p. 979.
} 
extranjeros acerca de la factibilidad y conveniencia de formular un Plan Regulador, basado en los criterios del "urbanismo moderno", una disciplina tan amplia, indeterminada como ambiciosa (RIGOTTI, 2015). Los planes debían vislumbrar el desarrollo futuro del tejido de la ciudad más allá de los límites administrativos actuales, corregir el casco urbano reglamentando las construcciones para intentar aminorar los efectos de la especulación inmobiliaria y proyectar barrios fuera de la zona central o consolidada de la ciudad.

En este ensayo de reconfiguración habitacional y funcional, la producción de espacios libres vertebrados por la ribera del Paraná conjugaría el saneamiento higiénico y la estética paisajística. La ordenanza número 58, promulgada en octubre de 1929, preveía la preparación de un Expediente Urbano a entregar en ocho meses y un Plan Regulador con su correspondiente memoria descriptiva a los dieciocho meses de la escrituración de la ordenanza-contrato (ARCHIVO MUNICIPAL DE DIGESTOS Y ORDENANZAS DE ROSARIO, 24 ago. 1929, f. 14) ${ }^{15}$. Dicha normativa estipulaba que los especialistas actuarían como asesores de la municipalidad en los asuntos contemplados por el Plan a discutirse en el Concejo Deliberante con el propósito de establecer soluciones provisionales, que luego serían integradas a la concepción final, resultante de la planificación. El Plan se presentaba a sí mismo como un proyecto en primer término orgánico, pero con cierta versatilidad, es decir, capaz de atender a las "modificaciones que resulten necesarias en el futuro", pero que apuntaba con firmeza a la resolución de los problemas de la coyuntura (DELLA PAOLERA; GUIDO; FARENGO, 1935, p. 10). Sus objetivos estaban colocados, especialmente, en recobrar la unidad perdida en la ciudad, generar una solución de continuidad para el eje norte-sur y reconfigurar los límites de la zona oeste, emplazando allí una circunvalación, algunas reservas boscosas, plantas industrias e instalaciones diversas. El territorio de la jurisdicción municipal habría de ser domesticado a través de los cálculos de la ingeniería y la estética de la arquitectura.

El Plan afirmaba que Rosario había alcanzado un estado de gran desorganización urbanística. Si bien, por sí mismo, un plan no era capaz de volatilizar las causas de las falencias de las urbes, el encadenamiento del proyecto en una línea de acción que trascendiera varias generaciones tendría resultados favorables en el largo plazo. Dentro

15 ARCHIVO MUNICIPAL DE DIGESTOS Y ORDENANZAS DE ROSARIO. Expedientes Terminados del Honorable Concejo Deliberante. Agosto. "Proyecto de Ordenanza sobre el Expediente Urbano y el Plan Regulador y de Extensión de la ciudad". 24 ago. 1929, f. 14. 
de las cuestiones que requerían una resolución urgente, figuraba la de los espacios verdes, que constituían una pieza fundamental en la calidad de vida urbana, sirviendo como lugares "para la higiene, el desahogo y el esparcimiento de la población." (DELLA PAOLERA; GUIDO; FARENGO, 1935, p. 12-13). En estos espacios se conjugaban una serie de expectativas vinculadas con el bienestar urbano. Cumplirían funciones sociales, al ofrecer espacios para el ocio y la contemplación; funciones urbanísticas y paisajísticas, al producir cortes, mediante la masa vegetal, necesarios para la descongestión y la legibilidad del entramado urbano; y funciones ecológicas, al servir como hábitat para la flora y la fauna, y regular el microclima de la ciudad.

En el caso de Rosario, el problema de la insuficiencia e inadecuación de los espacios libres se engarzaba directamente con los males provenientes del estrangulamiento urbano por el sistema ferroportuario, las malas condiciones de la vivienda popular, el aislamiento de los barrios y la ineficacia de las vías de transporte. En el fondo y como lo hiciera notar Hegemann (1931), el problema del espacio verde era una cuestión en primer lugar cuantitativa y en segundo término distributiva. El Plan Regulador recupera los números que en 1932 expuso el concejal Devoto. Rosario contaba con un misérrimo $0,8 \%$ de superficies verdes en comparación con el $20 \%$ que aconsejaba el urbanismo "científico". A pesar de su gran tamaño, el Parque de la Independencia se mostraba incapaz de aliviar las necesidades de una población asentada en las inmediaciones de un curso fluvial y paradójicamente privada del uso de la ribera. Asimismo, las plazas existentes habían funcionado bien para una Rosario antigua, de dimensiones, flujos y población más bien modestos. La edificación fue fagocitando los intersticios entre la costa, las vías férreas y el verde, dejando como resultado una masa urbana inconexa y heterodoxa que configuraba un entorno ambiental y material poco amables con la salud de los cuerpos que la habitaban (DELLA PAOLERA; GUIDO; FARENGO, 1935, p. 12-14).

El problema del verde era higiénico, cuantitativo y relacional. Más arriba se ha hecho mención al papel crucial que poseían la circulación del aire, el entorno vegetal y la exposición lumínica en el pensamiento higienista. Una perspectiva cuantitativa aplazaba cualquier discusión cualitativa: el número y el tamaño de los espacios verdes estaban por encima de las decisiones en torno a su calidad y localización. En consecuencia, resultaba perentorio adquirir terrenos sin edificación, evitando las dilaciones de los tiempos políticos. Finalmente, el aspecto relacional del problema verde se refería a la necesidad de disponer los parques dentro de conjuntos más amplios a los 
que se llamó sistemas, que estarían “[...] equilibradamente distribuidos dentro de las zonas de edificación y complementados por la incorporación de playas, balearios y otros lugares propicios de la costa [...]." (DELLA PAOLERA; GUIDO; FARENGO, 1935, p. 14). Por fortuna, en palabras de los gestores del Plan, la base económica para la ejecución pronta del proyecto había quedado a disposición de los proyectos, a partir de la letra de la Ley 2466 de Parques y Paseos de Santa Fe, que destinaba $\$ 6.000 .000 \mathrm{~m} / \mathrm{n}$ para espacios verdes en Rosario (DELLA PAOLERA, GUIDO; FARENGO, 1935, p. 10).

La solución para el problema del espacio verde no podía seguir el "[...] ejemplo verdaderamente desastroso de Buenos Aires [...]" ni recurrir a la instalación de plazas y parques pequeños y aislados característicos de "[...] concepciones urbanistas del pasado [...].” (DELLA PAOLERA; GUIDO; FARENGO, 1935, p. 49). El recurso utilizado por los mentores del Plan Regulador fue el park-system, entendido como un sistema de vastos espacios verdes "casi en estado natural”, vinculados entre sí y con otros espacios de menor porte a través de los park-ways (avenidas-parques). En la letra del diseño, el sistema de parques podía resolver los males locales de tres formas: ejerciendo una función higiénico-estética, sirviendo como complemento del sistema vial y actuando como un recurso económico, ya que implicaba la adquisición de terrenos baratos y no urbanizables para la construcción de las reservas vegetales (DELLA PAOLERA; GUIDO; FARENGO, 1935, p. 49). El sistema general de parques se distribuiría en cuatro grandes zonas libres, articuladas y localizadas con racionalidad y equidistancia respecto a los núcleos de población.

La red verde se ubicaría al norte y al sur de la ciudad, dejando al centro sin grandes parquizaciones. Debido a que "las construcciones densas y el relativamente alto valor del terreno les restarían posibilidades de llevarse a cabo", el Parque de la Independencia era suficiente. Esto obedecía al "criterio general" del Plan que buscaba "realizar una obra práctica en la forma menos onerosa para la ciudad." (DELLA PAOLERA; GUIDO; FARENGO, 1935, p. 27-28). El sistema general de parques se proyectaba dividido en cuatro grandes zonas boscosas articuladas con espacios verdes de menores dimensiones, distribuidos según las necesidades de las poblaciones de los distintos barrios (DELLA PAOLERA; GUIDO; FARENGO, 1935, p. 50-55).

Al norte y recorriendo la costa del Paraná, se incorporaría una zona dedicada a reservas boscosas, siendo, desde la creación del Parque Independencia, “[...] la obra de mayor provecho que se haga para la recreación higiénica y esparcimiento de los 
habitantes". Ese espacio, de características inmejorables, podría ser habilitado en las inmediaciones. Según los técnicos, ese habría de ser el parque más importante vinculado a la ciudad, contando con una fronda inigualable, vista al río y escasos costos de habilitación, esta franja serviría para la recreación veraniega y contaría con instalaciones variadas. Por otra parte, la canalización y habilitación de la cuenca del arroyo Ludueña complementaría este espacio verde de gran tamaño con el sistema norte lindero al río, compartiendo sus costos ventajosos y el potencial de su flora. Sumado a esto, se proyectaba un aeródromo en este espacio y la venta a particulares de sus sectores saneados sobrantes (regresando algunos de los costos asumidos por la municipalidad). Al sur, la tercera zona privilegiada por un potencial estético-higiénico estaba conformada por las bellas y grandes quebradas del Saladillo, “[...] uno de los sitios más pintorescos de nuestra ciudad". La región meridional sería, como las otras, acondicionada para el esparcimiento de los habitantes de los suburbios vecinos.

Finalmente, también al sur, se recuperarían las barrancas del Paraná pertenecientes a la zona de la vecina localidad de Alvear. Estos cuatro espacios funcionarían como los cimientos del sistema de parques que, unidos por avenidas nutridas de verde, envolverían a la ciudad como una especie de antídoto al abrazo del ferrocarril que rodeaba a la primera urbanización de Rosario. Como complemento del entramado arbóreo, se proyectaba, asimismo, acondicionar la isla del Espinillo como espacio verde que constituiría otro sitio de recreo y contaría también con un aeródromo. En torno a este enlace de atolones de naturaleza que oxigenaría a la ciudad, circulaba la idea de una avenida costanera. Reunir las barrancas para dominar la enorme potencialidad que ofrecía el Paraná no era una idea nueva, pero el Plan Regulador discriminaba entre los distintos espacios: la recuperación plena de las barrancas del río como espacios parquizables y la habilitación de la zona de islas como campo estratégico de batalla contra los mosquitos y como zonas de espacios verdes, balnearios y campos de deportes. Los pilares verdes de la ciudad, unidos por sus respectivos park-ways conformarían una serie de círculos concéntricos que habrían de transformar no solo la morfología, sino la calidad de vida de la ciudad.

El efecto del plan Regulador de 1935 sobre los espacios verdes fue fundamentalmente retórico, sus formulaciones no llegaron a plasmarse. En parte el plan resultó imposible porque trabajaba sobre las dos interfaces que habían dado vida a la ciudad: el puerto y el ferrocarril, dos líneas y terminales de transportes que estaban concesionadas a capitales extranjeros. La naturaleza de esas concesiones hizo inviable la 
mayor parte de las proposiciones del plan. Algunas de sus conceptos, especialmente los referidos a la recuperación de la costa, fueron retomados, aunque bajo presupuestos funcionalistas en el Plan Regulador de 1968 y de diseño arquitectónico en el Plan Director de 1991. En este último documento, el espacio verde aparece ya insinuando su nuevo carácter conceptual de dispositivo polifuncional y módulo fuertemente enlazado con la cuestión cultural que adquirió el espacio público luego de la inauguración del parque España en 1992 (ROLDÁN, PASCUAL; VERA, 2016).

Imagen 3 - Plan Regulador de Rosario. Plano sobre espacios verdes proyectados

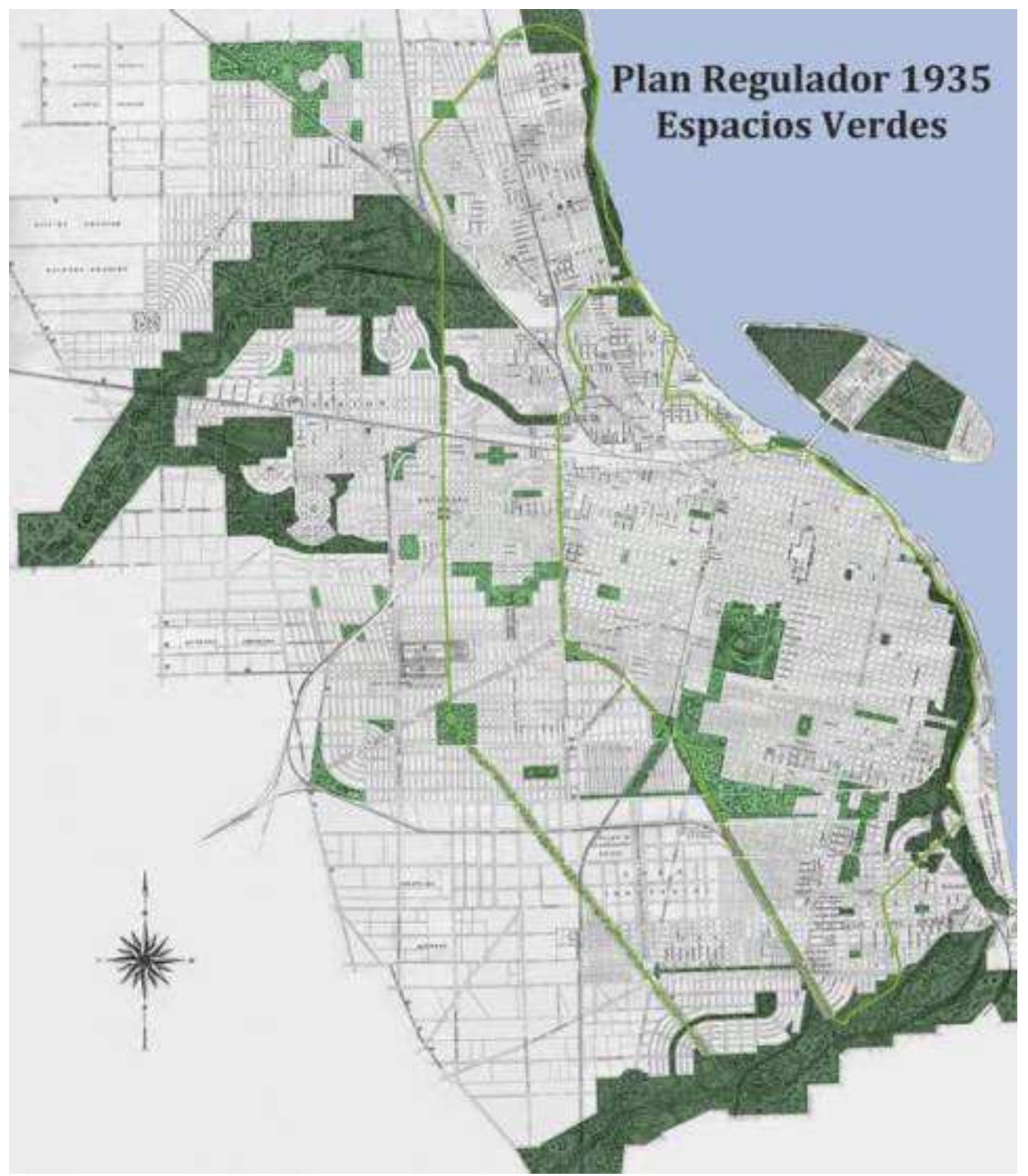

Fuente: Della Paolera; Guido; Farengo, 1935. 


\section{Conclusiones}

Este artículo recupera el proceso histórico de desenvolvimiento de las ideas acerca de los espacios verdes o espacios libres en las formas de imaginar y planear lo urbano durante la primera mitad del siglo XX, para mostrar sus diferencias, discontinuidades y alteridades con respecto a las formulaciones más actuales del espacio público. De hecho en ninguno de los documentos consultados, tanto sean series editadas o inéditas de debate parlamentario o de documentación relativa a planificación y proyectos urbanos, aparece el binomio conceptual espacio público. Este hecho demuestra la inexistencia de esa conjunción de vocablos para designar a los parques y las plazas. En cambio aparece con frecuencia la nominación de espacio verde y con una recurrencia menor la de espacio libre.

El cuerpo del trabajo se concentró en la recapitulación de la matriz higienista y paisajística que dominó la construcción de los espacios verdes entre 1900 y 1930. En ese período es posible observar cómo los miembros de las clases dominantes, los médicos higienistas y los paisajistas, alternativamente, apelaban a dos ideas para impulsar estos proyectos. Por un lado, argumentaban que las necesidades de la salud pública urbana y la habitación popular tornaban indispensables la construcción de parques. El vigor de la población, la supresión de algunas enfermedades y la posibilidad de que los cuerpos de las clases subalternas trabajaran de forma continua retribuirían cualquier inversión que tuviera que desplegarse en la adquisición y acondicionamiento de los terrenos por parte del municipio. Por otra, había un componente, tan solo invocado lateralmente, que se vinculaba con la cuestión de la distinción social. La construcción de parques, en tanto que paisajes y jardines incrustados en la urbanización, permitiría el desahogo y la figuración de las clases dominantes. Sin embargo, estos objetivos sólo se mencionaban como compensación a las inversiones necesarias para la expropiación o adquisición de los terrenos. Las concesiones a distintas entidades privadas (clubes como Jockey Club de Rosario, Club Atlético Newell's Old Boys y Gimnasia y Esgrima de Rosario) no sólo permitirían incrementar la atracción e interés sobre estos espacios, sino que brindarían la posibilidad de mantenerlos acondicionados sin la necesidad de producir una intervención/inversión por parte de la administración municipal.

Sin desaparecer por completo ni repentinamente, hacia mediados de los años 1930s., esta concepción higiénico-paisajística comenzó a habitar fragmentariamente y a 
declinar ante las formas de pensar el problema del espacio verde y libre promovidas por el urbanismo. Las ambiciones del urbanismo, respecto a su capacidad de regular el crecimiento de las ciudades, se desplegaron en las décadas siguientes, hasta que, también, la etapa peronista-desarrollista (1945-1974), que trazó una especie de complicidad entre la técnica, el Estado y la planificación, generó nuevas reconversiones y desplazamientos en el tratamiento de los problemas urbanos.

La propuesta del sistema de parques, en sentido práctico, aparece como la heredera de las miradas urbanísticas que veían en una contraparte bucólica de la traza urbana una posible salvación de la ciudad y de sus habitantes. Funcionando como una incardinación del campo dentro de la ciudad, este sistema lograría reformar, desde la morfología, las conductas y los rumbos de vida de los habitantes de una ciudad con riesgo de ingresar en un proceso de desorganización y anomia. Otra preocupación, quizá algo más accesoria, que atañía al complejo de parques y espacios verdes, abordado por el Plan Regulador de 1935, era la localización de conjuntos monumentales y artefactos culturales. La planificación de una topografía de estatuas y monumentos era entendida, sobre todo, desde el Centenario (1910), como necesaria para que la sociedad internalizase los valores morales y cívicos de la Nación en contra del cosmopolitismo y las ideas foráneas disruptivas, que en Rosario encarnaban en la poderosa inmigración procedente de ultramar. En la factura del Plan, la "pedagogía de las estatuas" se conjugaba con la pedagogía del verde, funcionando como un perímetro que debería no sólo servir de ambiente para las clases dominantes, sino contener y encauzar las acciones de las clases subalternas, imprescindibles para el funcionamiento de la máquina del crecimiento económico y cada vez más presentes en el espacio cotidiano de la ciudad. En parte, esta matriz de pensamiento urbano-monumental fue recuperada por el principal redactor del Plan, el rosarino Ángel Guido, al momento de proyectar, en 1939, el Monumento Nacional a la Bandera. Años más tarde y con el apoyo financiero y cultural del peronismo, el proyecto sería redimensionado para que alcanzara el volumen y la escala de monumento urbano.

En el Plan Regulador, dispositivo de representación y proyección urbanas, los espacios verdes cumplían una función moral: salvar los habitantes de la ciudad de los "desajustes" urbanos de una ciudad modernizada, cuyos efectos nocivos quedaban exacerbados por la falta de una reglamentación y un control responsables sobre el crecimiento de las edificaciones. Las masas constituían una nueva e irrecusable realidad, un dato con el que el urbanismo debía necesariamente que trabajar. El 
paliativo para las penurias económicas se amalgamaba a la reforma social en la figura de los parques, plazas y balnearios: “[...] dotar a tiempo de espacios libres a los grandes centros urbanos, es una obra excelente tanto desde el punto de vista humanitario como desde el puro y simplemente financiero." (DELLA PAOLERA; GUIDO; FARENGO, 1935, p. 54). En esas manchas verdosas del plano y el plan, podría encaminarse el tiempo libre de las nuevas masas que emergían embrionariamente en los años 1920 y que abundarían en la historia urbana y política de las siguientes décadas de la historia Argentina (ROLDÁN, 2012).

El artificio, en tanto que construcción humana consciente, del espacio verde en el Plan Regulador de 1935, retoma la premisa fundamental del urbanismo de ser más que la suma de soluciones parciales, constituyendo un tratamiento integral de los problemas urbanos. Si bien sus efectos fueron más fragmentarios de lo que sus autores hubieran deseado, la misma idea de totalidad operó como un móvil para la intervención gubernamental en materia de planificación. Actualmente, las nuevas planificaciones estratégicas han abandonado todo horizonte holístico y han cortado las relaciones con el universo de la utopía definida como cambio social y urbano. Por otro lado, quizá la dimensión espectacular y escenográfica, aunque fragmentada y acotada a sectores específicos y partes de ciudad, sea lo que las nuevas propuestas de espacio público de alta calidad recuperan de esas formas iniciales. En la historia de los espacios verdes y los espacios públicos, existe un hiato o una discontinuidad visible, que aún requiere de un estudio más detallado y capaz de problematizar y calibrar esas relaciones de extrañamiento y afinidad entre los sistemas verdes y los fragmentos del espacio públicos esparcidos en la trama urbana actual. 


\section{REFERENCIAS}

\section{Fuentes primarias}

ARCHIVO MUNICIPAL DE DIGESTOS Y ORDENANZAS DE ROSARIO. Diario de Sesiones del Honorable Concejo Deliberante. 1932. "Proyecto de ordenanza del concejal Galaretto sobre funciones de la dirección de Parques y Paseos". 2 sept. 1932, p. 979.

ARCHIVO MUNICIPAL DE DIGESTOS Y ORDENANZAS DE ROSARIO. Expedientes Terminados del Honorable Concejo Deliberante. "El intendente Lamas sobre el Parque Independencia”. 24 jun. 1900, f. 292.

ARCHIVO MUNICIPAL DE DIGESTOS Y ORDENANZAS DE ROSARIO. Expedientes Terminados del Honorable Concejo Deliberante. Octubre 1909. "El intendente Quiroga sobre Joseph Bouvard y un plan para Rosario". 4 oct. 1909, f. 308.

ARCHIVO MUNICIPAL DE DIGESTOS Y ORDENANZAS DE ROSARIO. Expedientes Terminados del Honorable Concejo Deliberante. Mayo 1910, t. 2. "Boleto de Compra venta ad Referéndum de terrenos para la construcción del Parque Arroyito". 1 abr. 1910, f. 327.

ARCHIVO MUNICIPAL DE DIGESTOS Y ORDENANZAS DE ROSARIO. Expedientes Terminados del Honorable Concejo Deliberante. Agosto-diciembre 1910, t. 2. "La Sociedad Anónima el Arroyito disponiendo la venta de terrenos a la Municipalidad para la formación del Parque Arroyito". 11 ago. 1910, f. 131.

ARCHIVO MUNICIPAL DE DIGESTOS Y ORDENANZAS DE ROSARIO. Expedientes Terminados del Honorable Concejo Deliberante. Mayo 1913, t. 1. "Presentación del Plano de Rosario de Joseph Bouvard frante al Concejo Deliberante". (París) 10 mar. 1911, f. 353-354.

ARCHIVO MUNICIPAL DE DIGESTOS Y ORDENANZAS DE ROSARIO. Expedientes Terminados del Honorable Concejo Deliberante. Mayo 1913, t. 2. "Secretario de la Intendencia eleva el proyecto del Ing. Carlos Thays del Parque Recreo Arroyito". 23 sept. 1913, f. 175.

ARCHIVO MUNICIPAL DE DIGESTOS Y ORDENANZAS DE ROSARIO. Expedientes Terminados del Honorable Concejo Deliberante. Mayo 1917. "Terrenos para el Parque Arroyito". 23 ab. 1917, f. 263.

ARCHIVO MUNICIPAL DE DIGESTOS Y ORDENANZAS DE ROSARIO. Expedientes Terminados del Honorable Concejo Deliberante. Mayo 1920, t. 1. "Pedido y Concesión del Club Regatas de terreno municipal en Barrio Arroyito". 14 may. 1920, f. 668-672.

ARCHIVO MUNICIPAL DE DIGESTOS Y ORDENANZAS DE ROSARIO. Expedientes Terminados del Honorable Concejo Deliberante. Diciembre 1923, t. 2. "Director de Parques y Paseos contesta petición del Club Sportivo solicitando terreno en el Parque Independencia”. 10 may. 1923, f. 199. 
ARCHIVO MUNICIPAL DE DIGESTOS Y ORDENANZAS DE ROSARIO. Expedientes Terminados del Honorable Concejo Deliberante. Agosto. "Proyecto de Ordenanza sobre el Expediente Urbano y el Plan Regulador y de Extensión de la ciudad". 24 ago. 1929, f. 14.

ARCHIVO MUNICIPAL DE DIGESTOS Y ORDENANZAS DE ROSARIO. Expedientes Terminados del Honorable Concejo Deliberante. Mayo 1932, t. 2. "Reservas boscosas y espacios libres. Proyecto del Concejal Ing. Juan Devoto". s/f, f. 2786.

CARRASCO, G. 1890. Del Atlántico al Pacífico y Un argentino en Europa: Cartas de viaje. Buenos Aires: Casa Editora Jacobo Peuser, 1890.

DELLA PAOLERA, Carlos M. El Plan Regulador de la "Aglomeración Bonaerense. La Razón, Buenos Aires, 11 y 18 de marzo de 1927.

DELLA PAOLERA, Carlos M. El parque urbano y sus alrededores. La Razón, Buenos Aires, 7 de enero de 1928.

DELLA PAOLERA, Carlos; GUIDO, Ángel; FARENGO, Adolfo. Plan Regulador y de Extensión. Memoria descriptiva y justificativa. Rosario: Municipalidad de Rosario, 1935.

MUNICIPALIDAD DE ROSARIO. Plan Urbano Rosario 2007-2017. Rosario: Municipalidad de Rosario. 2008.

PIGNETTO, Manuel. Memoria de Intendencia Abril 1925-Abril 1927. Rosario: Talleres gráficos La Velocidad, 1927.

QUIROGA, Isidro. Memoria de Intendencia de 1909. Rosario: Peuser, 1909.

RAWSON, Guillermo. Conferencias de Higiene Pública. París: Donnanette \& Hattu, 1876.

RAWSON, Guillermo. Informe sobre las condiciones de vida insalubre de los conventillos de Buenos Aires. Buenos Aires: Imprenta Oficial, 1885.

WILDE, Eduardo. Curso de Higiene pública. Buenos Aires: Imprenta y Librería de May, 1885.

Fuentes secundarias

AMENDOLA, Giandomenico. La ciudad posmoderna. Magia y miedo en las metrópolis contemporáneas. Madrid: Celeste Ediciones, 2000.

ARENDT, Hannah. La condición Humana. Barcelona: Paidós, 2007.

ARMUS, Diego. La idea de verde en la ciudad moderna. Buenos Aires 1870-1940. Entrepasados, Buenos Aires, n. 10, p. 7-29, 1996. 
ARMUS, Diego. Las colonias de vacaciones: de la higiene a la recreación. En: SCHARAGRODSKY, Pablo (Comp.). Miradas médicas sobre la cultura física en Argentina 1880-1970. Buenos Aires: Prometeo, 2014. p. 179-191.

BAUDRILLARD, Jean. Cultura y simulacro. Barcelona: Anagrama, 1978.

BECK, Ulrich. Libertad o capitalismo. Conversaciones con Johannes Willms. Barcelona: Paidós, 2002.

BORJA, Jordi. Revolución urbana y derechos ciudadanos: claves para interpretar las contradicciones de la ciudad actual. 2012. 534 f. Tesis (Doctoral en Geografía) Universidad de Barcelona, Facultad de Geografía e Historia, Departamento de Geografía Humana, Barcelona, 2012.

BORJA, Jordi; Manuel Castells. Local y global. La gestión de ciudades en la era de la comunicación. Madrid: Taurus, 2000.

CHARDON, Cristina. Transformaciones del espacio público: los actores, las prácticas, las representaciones. Buenos Aires: La Crujía, 2011.

CRASEMANN COLLINS, Christine. Werner Hegemann and the search for universal urbanism. Nueva York: W.W. Norton \& Company, 2005

DE CERTEAU, Michel. La invención de lo cotidiano. 1 artes del hacer. México: Universidad Iberoamericana, 2000.

DELGADO, Manuel. La ciudad mentirosa. Fraude y miseria del modelo Barcelona. Madrid: Libros de la Catarata, 2007.

DELGADO, Manuel. El espacio público como ideología. Madrid: Libros de la Catarata, 2011.

DERRIDA, Jacques. Espectros de Marx. Madrid: Trotta, 1995.

ENGELS, Friedrich. La situación de la clase obrera en Inglaterra en 1844. Buenos Aires: Futuro, 1965.

ENGELS, Friedrich. Sobre el problema de la vivienda. Buenos Aires: Ateneo, 1974.

FOUCAUlT, Michel. Foucault, M. Seguridad, Territorio y Población. Curso del Collège de France 1978. Buenos Aires: Fondo de Cultura Económica, 2006.

FOUCAULT, Michel. Nietzsche la genealogía y la historia. Valencia: Pre-textos, 1988.

FOUCAUlT, Michel. Seguridad, Territorio y Población. Curso de Collège de France 1977-1978. Buenos Aires: 2006.

GADAMER, Hans-Georg. Verdad y Método II. Salamanca: Ediciones Sigueme, 1996. 
GARCÍA CANCLINI, Néstor. Los imaginarios urbanos. Buenos Aires: Eudeba. 1998.

GORELIK, Adrián. El romance del espacio público. Alteridades, Ciudad de México, v. 18 , n. 36, p. 33-45, 2008.

GORELIK, Adrián. La grilla y el parque. Espacio público y cultura urbana en Buenos Aires, 1887-1936. Bernal: Universidad Nacional de Quilmes, 1998.

HABERMAS, Jürgen. Historia y crítica de la opinión pública. Barcelona: Gustavo Gilli, 1982.

HABERMAS, Jürgen. Ciencia y técnica como ideología. Barcelona: Anagrama, 1986.

HENAFF, Marcel; STRONG, Tracy (Eds.). Public Space and Democracy. Minneapolis: University of Minnesota Press, 2001.

JACOBS, Jane. Muerte y Vida de las grandes ciudades. Barcelona: Capitan Swing, 2011.

LANCIOTTI, Norma. De rentistas a empresarios. Inversión inmobiliaria y urbanización en la pampa argentina. Rosario 1880-1914. Santa Fe: Editorial de la Universidad Nacional del Litoral, 2009.

LEFEBVRE, Henri. EI derecho a la ciudad. Madrid: Península, 1969.

PASCUAL, Cecilia. Imágenes de la ciudad y las periferias. Configuraciones de lógicas y relaciones de segregación y estigmatización. Rosario 1886/7-1940. 2015. Tesis (Doctoral en Historia) - Universidad Nacional de Rosario, Facultad de Humanidades y Artes, Centro de Estudios Culturales Urbanos, Rosario, 2015.

RABOTNIKOF, Nora. El espacio público y la democracia moderna. Ciudad de México: Instituto Federal Electoral, 1997.

RIGOTTI, Ana María Las invenciones del urbanismo en la Argentina (1900-1960). Inestabilidad de sus representaciones científicas y dificultades para su profesionalización. Rosario: UNR-Editora, 2015.

ROLDÁN, Diego P. Ferrocarril, ciudad y urbanismo. In: BARRIERA, Darío G. (Dir.). Instituciones, Gobierno y Territorio. Rosario, de la Capilla al Municipio (17251930). Ediciones del ISHIR: Rosario, 2010. p. 181-189.

ROLDÁN, Diego P. La invención de las masas. Ciudad, corporalidades y culturas. Rosario, 1910-1945. La Plata: Universidad Nacional de la Plata, 2012.

ROLDÁN, Diego; PASCUAL, Cecilia; VERA, Paula. El espacio público urbano como concepto y materialidad propuestas, intervenciones $\mathrm{y}$ debates en Rosario. Estudios sociales contemporáneos, n. 13, p. 19-35, 2016.

SENNETT, Richard. El declive del hombre público. Barcelona: Península, 1977. 
SILVESTRI, Graciela; Aliata, Fernando. El paisaje como cifra de armonía: relaciones entre cultura y naturaleza a través de la mirada paisajística. Buenos Aires: Nueva Visión, 2001.

TOPALOV, Christian. La cuestión social a los problemas urbanos: los reformadores y la población de las metrópolis a comienzo del siglo XX. Revista Internacional de Ciencias Sociales, n. 125, p. 42-72, 1990.

VAINER, Carlos. Patria, empresa, mercancía. Notas sobre la estrategia discursiva del planeamiento estratégico. Revista Mundo Urbano [on-line], n. 14, 2004. Disponible: $<$ http://mundourbano.unq.edu.ar/index.php/ano-2001/58-numero-14/97-3-patria-empr esa-e-mercadoria>. Acceso en: 21 mar. 2014. 